\title{
Efficacy and safety of phenytoin versus clobazam as monotherapy for newly diagnosed epileptic patients
}

\author{
Saborni Dey', Anil Kumar Kem², Yatish ${ }^{3}$, Somya Agarwal ${ }^{4}$ \\ ${ }^{1}$ Associate Professor, Department of Pharmacology, ${ }^{2}$ Professor and H.O.D, ${ }^{3}$ Assistant Professor, ${ }^{4}$ Resident, \\ Department of General Medicine, Saraswathi Institute of Medical Sciences, Hapur, Uttar Pradesh, India
}

Background: Epilepsy is a chronic disorder characterized not only by recurrent seizures but also by a great variety of medical and psychosocial implications. Its burden to the patients and their families has been recognized and even the impact upon the community is vast. Aims and Objectives: The aim of the study was to compare the efficacy and safety of phenytoin and clobazam in monotherapy for the management of new onset, untreated epileptic patients. Materials and Methods: A 6 months, observational, comparative study was conducted on 60 adult patients with epilepsy. The eligible patients were given either phenytoin sodium (Group $A ; n=30$ ) in a loading dose of $15 \mathrm{mg} / \mathrm{kg}$ orally, followed by $5 \mathrm{mg} / \mathrm{kg} /$ day maintenance dose for 6 months while Group-B $(\mathrm{n}=30)$ received clobazam in a dose of $1 \mathrm{mg} / \mathrm{kg}$ oral loading dose followed by $0.5 \mathrm{mg} / \mathrm{kg} /$ day. Seizure frequency was evaluated and compared with baseline at 1, 2, 3, 4.5, 6 months along with adverse drug reaction assessment. Results: In Group $A$ mean pre-treatment baseline seizure frequency was $6.3 \pm 2.19$ and for Group B 5.80 \pm 2.22 . After 6 months, seizure frequency for Group $A$ $2.30 \pm 1.99$ and in Group B 1.30 \pm 1.91 . In Group B, there was a significantly higher reduction in seizure frequency $(P=0.001)$ than that of Group $A$. Both the drug groups significantly reduced the seizure frequency but Group B was found to be superior. Adverse drug reaction was more in Group A in comparison with Group B. The common side effects were drowsiness, weight gain, headache, tiredness, nausea and ataxia. Conclusion: Clobazam monotherapy had demonstrated better efficacy than phenytoin for the treatment of epilepsy and also well tolerated.

Key words: Clobazam; Epilepsy; Monotherapy; Phenytoin
Access this article online

Website:

http://nepjol.info/index.php/AJMS

DOI: 10.3126/ajms.v13i3.42550

E-ISSN: 2091-0576

P-ISSN: 2467-9100

Copyright (c) 2022 Asian Journal of Medical Sciences

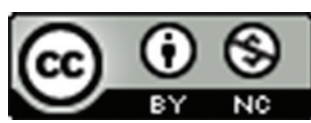

This work is licensed under a Creative Commons Attribution-NonCommercial 4.0 International License.

\section{INTRODUCTION}

Epilepsy is a chronic neurological disease characterized by recurrent unprovoked seizure affecting 50 million people worldwide and around 10 million people in India. ${ }^{1}$ Antiepileptic drug (AED) selection depends on the epilepsy diagnosis, seizure type with considerations for therapeutic efficacy, adverse effects, cost, availability along with an optimal quality of life. Treatment of epilepsy begins with monotherapy with a single anti-epileptic drug, but many non-responder patients require polytherapy and in some reports, $30 \%$ of patients continue to have seizures despite adequate drug therapy. ${ }^{2}$
The discovery of phenytoin in 1938 was a landmark achievement by Merritt and Putnam which showed great anticonvulsant activity without sedation and also cost-effective first-line drug. ${ }^{3}$ Phenytoin is used for generalized tonic clonic, partial, and other epilepsies and acts by prolonging the inactivated stage of voltagesensitive neuronal $\mathrm{Na}^{+}$channel by stabilizing the neuronal membrane.

Clobazam was introduced as an anxiolytic agent in 1975 but also having potent anticonvulsant properties. It is a benzodiazepine but differs from classic agents by the placement of nitrogen atom at positions 1 and 5 rather than 
1 and 4 in the second ring and act by potentiating GABA mediated inhibitory neurotransmission. This newer secondline drug is very effective in multidrug-resistant refractory epilepsy, partial and generalized seizures, febrile seizures, status epilepticus but may have side effects, abuse potential, tolerance. Again newer AEDs being more expensive than conventional AEDs, their affordability and availability is a major problem in developing countries like India.

In India, we are in need of a classic AED that provide complete control of seizure, less side effects and drug interactions, cost-effective, better tolerability, medication adherence and upgrade the quality of life. ${ }^{4}$ Though some studies in the Indian population have shown the proficiency of clobazam as an add on drug, data regarding monotherapy, efficacy, and safety in treatment regimens are limited. In spite of extensive literature search, we could not find any study comparing the effectiveness and safety of these two drugs in the Indian population for epilepsy treatment as monotherapy.

Therefore, our primary outcome of the study was to compare the reduction in seizure frequency and safety (secondary outcome) of phenytoin and clobazam monotherapy in newly diagnosed adult epileptic patients in a multi-speciality teaching hospital, SIMS, Hapur.

\section{Aims and objectives}

The aim of the study was to compare the reduction in seizure frequency and safety of phenytoin and clobazam monotherapy in untreated adult epileptic patients

\section{MATERIALS AND METHODS}

The study was executed in the Department of Pharmacology in collaboration with the Department of Medicine of Saraswathi Institute of Medical Sciences, Hapur, U.P.- a tertiary care teaching hospital.

After getting approval from Institutional Ethical Committee, a total of 99 patients were screened for the study. Out of them, who fulfilled the eligibility criteria 80 trial participants were recruited from the outpatient department of Epilepsy Clinic along with their written informed consent.

This observational, open-label, prospective, parallel-group study was regulated for 9 months of duration from March 2021 to December 2021. All the new cases of epilepsy of either sex, of the age groups between 18 and 46 years, with generalized or focal seizures with or without secondary generalization and were not already on AED therapy were included for the study. Patients with a concomitant serious systemic disorder, psychotic disorders, pregnant women, patients with a demonstrable cause of epilepsy and those unwilling to comply with follow-up schedules were excluded for the study.

Demographic details, diagnosis, seizure type, frequency of seizures, duration, epilepsy characteristics, medical history, details of their physical examination, and drug history were recorded with proper proforma. A comparison was done between two groups regarding various outcome parameters such as seizure type, family history, frequency of seizure per month, duration of seizures in minutes, and duration of illness in days.

A total sample size of 60 was taken and again in consideration of drop-outs and non-compliance of the patients, the sample size was increased up to 80 screened participant's for the study of 6 months.

The participants were divided into two equal groups- Group-A and Group-B containing 40 patients each. The patients of Group-A received phenytoin-sodium in a loading dose of $15 \mathrm{mg} / \mathrm{kg}$ orally (divided into three doses) on day 1 , followed by $5 \mathrm{mg} / \mathrm{kg} /$ day maintenance dose for 6 months or more. While the patients of Group-B received clobazam in a dose of $1 \mathrm{mg} / \mathrm{kg}$ oral loading dose followed by $0.5 \mathrm{mg} / \mathrm{kg} /$ day for 6 months of duration. The change in seizure severity, the dose of clobazam and phenytoin required, and development of side effects was followed up at 1, 2, 3, 4.5 and 6 months after initiation of therapy.

Routine investigations as complete blood count, liver and renal function tests, cranial CT scan and EEG were done to rule out any co-existing disease.

Our primary objective was to determine the percentage of improvement in the numbers and duration of seizures frequency that was calculated at each visit of follow-up at $0,1,2,3,4.5,6$ months. Assessment was carried out by guidelines of the International League Against Epilepsy and seizure frequency rate and duration were compared with baseline. ${ }^{5}$

The patients were considered to be Total responders if there were no seizures at the end of 6 months follow-up period, if the number of seizures reduced by $50-100 \%$ of the pre-treatment level - they were called Partial responders and were termed as Non responders if the seizures reduced by $<50 \%$ than baseline. The secondary objective was to monitor the adverse drug events and safety assessment.

The importance of compliance was explained and reinforced at each visit and monitored for adverse drug reactions with prompt management, uncontrolled break through seizure, or worsening of symptoms. 
Statistical anaysis

Statistical Package for Social Sciences Version 23.0 (SPSS/ PC; SPSS-23.0, Chicago, USA) was used for data analysis and calculations. The results were compared between groups by nonparametric Wilcoxon Signed-rank test, Mann-Whitney U test, Fisher's exact test and Parametric Paired and Unpaired t-test, Chi-square test.

\section{RESULTS}

Out of the 80 study participants, 60 patients completed regular follow-up schedule of which $n=30$ were in phenytoin treated Group A (5 lost to follow-up, 5 discontinued intervention), while $n=30$ were also in clobazam treated Group B (6 lost to follow-up, 4 discontinued intervention). The data were analyzed using last observation carried forward method that is 60 patient's data were analyzed.

Table 1 showed the baseline demographic characteristics and clinical parameters, that were compared in two treatment groups and there were no statistically significant differences between these groups.

Table 1 also showed that there were 37 (61.67\%) males and $23(38.33 \%)$ females aged between 18-46 years (average mean age $24.83 \pm 6.79$ ) included in the study.

The seizure type included generalized tonic clonic seizure $(n=35)$, complex partial seizure $(n=18)$ and 7 patients had other seizure type.

There was no statistically significant difference between Group A and Group B in baseline seizure frequency per month, seizure duration in minutes, and duration of illness (days).
Table 2 had showed in Group A, mean pre-treatment baseline seizure frequency was $6.3 \pm 2.19$ at 0 month, $3.16 \pm 1.60$ at 1 month, $2.10 \pm 1.16$ at 2 months, $1.83 \pm 1.18$ at 3 months, $1.80 \pm 1.40$ at 4.5 months, and $2.30 \pm 1.99$ at 6 months.

In Group B, mean pre-treatment baseline seizure frequency was $5.80 \pm 2.22$ at 0 month, $3.37 \pm 1.85$ at 1 month, $2.37 \pm 1.27$ at 2 months, $1.67 \pm 1.58$ at 3 months, $1.33 \pm 1.58$ at 4.5 months and $1.30 \pm 1.91$ at 6 months.

Between-group comparison (paired T Test) showed that both the drug groups significantly decreased the seizure frequency at different time interval but Group B $(\mathrm{P}<0.01$, $\mathrm{P}=0.001)$ was considered more superior than Group A.

Figure 1 demonstrated the comparative efficacy of the drugs at various time interval and compliance. It showed that there was a statistically significant difference between two groups where Group B was found more efficacious clinically and statistically.

After 6 months follow up, Group A had, 30.00\% seizure freedom (Total responder) compared to $53.33 \%$ in Group B; while $\geq 50 \%$ seizure reduction (Partial responders) were $26.67 \%$ equal in each groups. Again, $43.33 \%$ of patients in Group A had seizure reduction $<50 \%$ (Non responders) compared to $20.0 \%$ in Group B as described in Table 3.

After comparing between two groups there was no statistically significant difference seen. $(\mathrm{P}=0.103)$.

Table 4 showed that out of total 48 ADRs, 32 (66.67\%) ADRs were reported in Group A while 16 (33.33\%) ADRs in Group B.

\begin{tabular}{|c|c|c|c|}
\hline \multirow[t]{2}{*}{ Demographic Characteristics } & \multicolumn{2}{|c|}{ Study Groups } & \multirow[t]{2}{*}{$P$ value } \\
\hline & Group-A & Group-B & \\
\hline Age (in years) Mean $\pm S D$ & $25.27 \pm 8.41$ & $25.4 \pm 8.07$ & 0.95 \\
\hline \multicolumn{4}{|l|}{ Gender } \\
\hline Male & 13.00 & 10.00 & \multirow[t]{2}{*}{0.426} \\
\hline Female & 17.00 & 20.00 & \\
\hline Weight (in kg) Mean \pm SD & $51.2 \pm 8.77$ & $55.47 \pm 7.99$ & 0.054 \\
\hline \multicolumn{4}{|l|}{ Type of Seizure } \\
\hline CPS & 10.00 & 8.00 & \multirow[t]{3}{*}{0.733} \\
\hline GTCS & 16.00 & 19.00 & \\
\hline Others & 4.00 & 3.00 & \\
\hline \multicolumn{4}{|l|}{ Family History } \\
\hline Postive & 13 & 12 & \multirow[t]{2}{*}{0.793} \\
\hline Negative & 17 & 18 & \\
\hline Seizure Frequency/Month Mean $\pm S D$ & $6.37 \pm 2.19$ & $5.8 \pm 2.22$ & 0.324 \\
\hline Seizure duration (in minutes) Median (IQR) & $9(5-10)$ & $8(4.7-10)$ & 0.775 \\
\hline Duration of illness (in days) Median (IQR) & $45(33-76.25)$ & $45(33.7-60)$ & 0.994 \\
\hline
\end{tabular}




\begin{tabular}{|c|c|c|c|c|c|c|c|}
\hline Groups & $\begin{array}{l}\text { Follow } \\
\text { Ups }\end{array}$ & $\begin{array}{l}\text { Comparison of Improvements in different follow } \\
\text { ups with Baseline Seizure Frequency }\end{array}$ & Mean & $\mathbf{N}$ & $\begin{array}{l}\text { Std. } \\
\text { Deviation }\end{array}$ & $\begin{array}{l}\text { Paired t-test } \\
\text { value }\end{array}$ & $P$ value \\
\hline \multirow[t]{10}{*}{ Group A } & \multirow{2}{*}{$\begin{array}{l}\text { Paired at } 1 \\
\text { month }\end{array}$} & Pre-treatment Baseline Seizure Frequency at 0 Month & 6.3667 & 30 & 2.19 & \multirow[t]{2}{*}{9.80} & \\
\hline & & Seizure Frequency at 1 Month & 3.1667 & 30 & 1.60 & & \\
\hline & \multirow{2}{*}{$\begin{array}{l}\text { Paired at } 2 \\
\text { months }\end{array}$} & Pre-treatment Baseline Seizure Frequency at 0 Month & 6.3667 & 30 & 2.19 & \multirow[t]{2}{*}{13.91} & \\
\hline & & Seizure Frequency at 2 Months & 2.1000 & 30 & 1.16 & & \\
\hline & \multirow{2}{*}{$\begin{array}{l}\text { Paired at } 3 \\
\text { months }\end{array}$} & Pre-treatment Baseline Seizure Frequency at 0 Month & 6.3667 & 30 & 2.19 & \multirow[t]{2}{*}{12.55} & \\
\hline & & Seizure Frequency at 3 Months & 1.8333 & 30 & 1.18 & & \\
\hline & \multirow{2}{*}{$\begin{array}{l}\text { Paired at } 4 . \\
5 \text { months }\end{array}$} & Pre-treatment Baseline Seizure Frequency at 0 Month & 6.3667 & 30 & 2.19 & \multirow[t]{2}{*}{12.54} & \\
\hline & & Seizure Frequency at 4.5 Months & 1.8000 & 30 & 1.40 & & \\
\hline & \multirow{2}{*}{$\begin{array}{l}\text { Paired at } 6 \\
\text { months }\end{array}$} & Pre-treatment Baseline Seizure Frequency at 0 Month & 6.3667 & 30 & 2.19 & \multirow[t]{2}{*}{9.10} & \\
\hline & & Seizure Frequency at 6 Months & 2.3000 & 30 & 1.99 & & \\
\hline \multirow[t]{10}{*}{ Group B } & \multirow{2}{*}{$\begin{array}{l}\text { Paired at } 1 \\
\text { months }\end{array}$} & Pre-treatment Baseline Seizure Frequency at 0 Month & 5.8000 & 30 & 2.22 & \multirow[t]{2}{*}{7.35} & \multirow[t]{10}{*}{0.001} \\
\hline & & Seizure Frequency at 1 Month & 3.3667 & 30 & 1.85 & & \\
\hline & \multirow{4}{*}{$\begin{array}{l}\text { Paired at } 2 \\
\text { months } \\
\text { Paired at } 3 \\
\text { months }\end{array}$} & Pre-treatment Baseline Seizure Frequency at 0 Month & 5.8000 & 30 & 2.22 & \multirow[t]{2}{*}{9.77} & \\
\hline & & Seizure Frequency at 2 Months & 2.3667 & 30 & 1.27 & & \\
\hline & & Pre-treatment Baseline Seizure Frequency at 0 Month & 5.8000 & 30 & 2.22 & \multirow[t]{2}{*}{10.97} & \\
\hline & & Seizure Frequency at 3 Months & 1.6667 & 30 & 1.58 & & \\
\hline & Paired at 4. & Pre-treatment Baseline Seizure Frequency at 0 Month & 5.8000 & 30 & 2.22 & \multirow[t]{2}{*}{10.85} & \\
\hline & 5 months & Seizure Frequency at 4.5 Months & 1.3333 & 30 & 1.58 & & \\
\hline & Paired at 6 & Pre-treatment Baseline Seizure Frequency at 0 Month & 5.8000 & 30 & 2.22 & \multirow[t]{2}{*}{11.16} & \\
\hline & months & Seizure Frequency at 6 Months & 1.3000 & 30 & 1.91 & & \\
\hline
\end{tabular}

If $\mathrm{P}<0.05$, there is a statistically significant difference between Mean Baseline Seizure frequency versus Mean Seizure frequency at different time interval (Paired $t$-test)

\begin{tabular}{|c|c|c|c|c|c|}
\hline \multirow{2}{*}{$\begin{array}{l}\text { Therapy After } 6 \text { months } \\
\text { (Group Cross-tabulation) }\end{array}$} & \multicolumn{2}{|c|}{ Study Groups } & \multirow[t]{2}{*}{ Total } & \multirow[t]{2}{*}{ Chi-square value } & \multirow[t]{2}{*}{$P$ value } \\
\hline & Group A & Group B & & & \\
\hline Seizure Freedom (Total Responders) & $\begin{array}{c}9 \\
36.0 \%\end{array}$ & $\begin{array}{c}16 \\
64.0 \%\end{array}$ & $\begin{array}{c}25 \\
100.0 \%\end{array}$ & & \\
\hline Seizure Reduction $\geq 50 \%$ (Partial Responders) & $\begin{array}{c}8 \\
50.0 \%\end{array}$ & $\begin{array}{c}8 \\
50.0 \%\end{array}$ & $\begin{array}{c}16 \\
100.0 \%\end{array}$ & & \\
\hline Seizure Reduction< $<50 \%$ (Non Responders) & $\begin{array}{c}13 \\
68.4 \%\end{array}$ & $\begin{array}{c}6 \\
31.6 \%\end{array}$ & $\begin{array}{c}19 \\
100.0 \%\end{array}$ & & \\
\hline Total & $\begin{array}{c}30 \\
50.0 \%\end{array}$ & $\begin{array}{c}30 \\
50.0 \%\end{array}$ & $\begin{array}{c}60 \\
100.0 \%\end{array}$ & 4.35 & 0.103 \\
\hline
\end{tabular}

The commonest side effect was drowsiness $(\mathrm{n}=19)$ followed by weight gain ( $n=11)$, headache $(n=6)$, tiredness $(n=4)$, nausea $(n=3)$, ataxia $(n=3)$, skin rash $(n=2)$.

Adverse event rate was more in phenytoin group compared to clobazam group but it was statistically insignificant.

\section{DISCUSSION}

In this study, new-onset epilepsy patients were treated by monotherapy of phenytoin and clobazam in two treatment groups and their therapeutic efficacy and safety were compared.

In our study, $61.67 \%$ of patients were male and $38.33 \%$ were female. However, many other studies also showed male predominance. ${ }^{6}$ The average mean age of the patients was 24.83 years, while GTCS was the most frequently occurring seizure type. Similar findings were supported by many other study reports. ${ }^{7,8}$
According to Indian guidelines of epilepsy, treatment should start with older anti-epileptics like phenytoin as first-line drug due to less costly and well-known side effects. ${ }^{9}$ The current trend is to add other drugs like clobazam until acceptable improvement occurs, but may have a mediocre success rate of only $10 \%$ while increasing detrimental ADRs. The use of a single antiepileptic drug at the minimally effective dose, up-to the maximum tolerated dose, is the suitable therapy for patients.

Phenytoin is one of the most commonly used drugs worldwide especially for partial and generalized tonic-clonic seizures as mono or polytherapy. Clobazam was frequently prescribed as add-on therapy, but it had validated efficacy as monotherapy as well. ${ }^{10-12}$

After 6 months follow up, $9(30.00 \%)$ patients had complete seizure freedom, $8(26.67 \%)$ patients had $\geq 50 \%$ seizure reduction and $13(43.33 \%)$ patients had $<50 \%$ seizure 


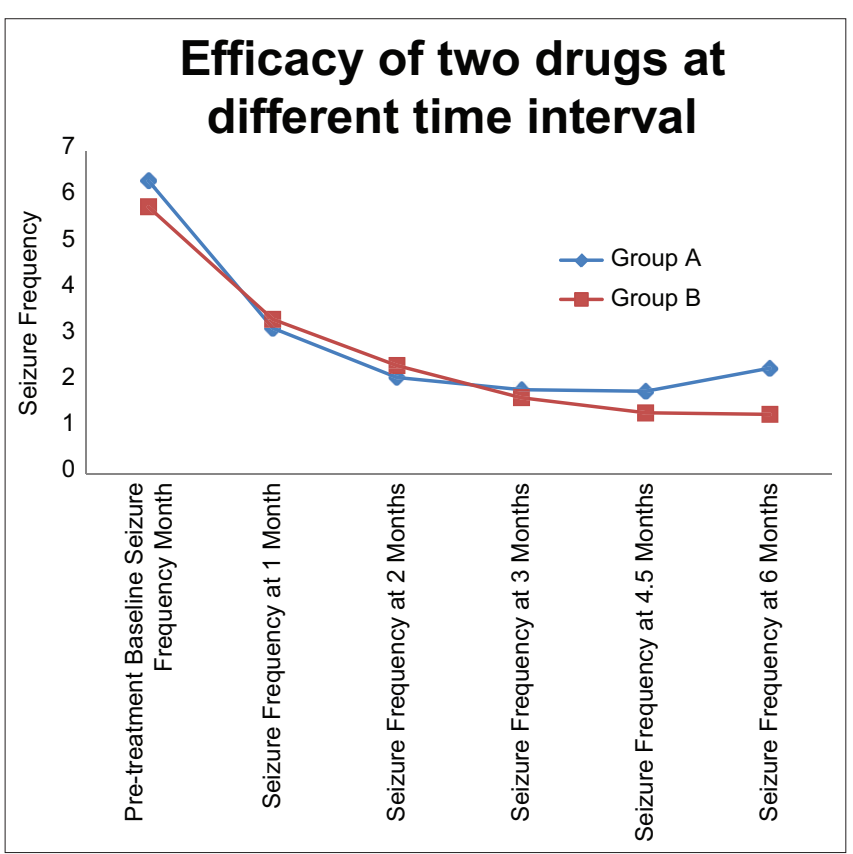

Figure 1: Comparative efficacy of phenytoin and clobazam in new-onset epileptic patients in different follow-ups

\begin{tabular}{|c|c|c|c|c|}
\hline $\begin{array}{l}\text { Adverse } \\
\text { Events }\end{array}$ & $\begin{array}{c}\text { Group-A } \\
\text { (Phenytoin } \\
\text { treated); } \\
n=30\end{array}$ & $\begin{array}{c}\text { Group-B } \\
\text { (Clobazam } \\
\text { treated); } \\
n=30\end{array}$ & Total & $P$ value \\
\hline Drowsiness & $\begin{array}{c}12 \\
37.5 \%\end{array}$ & $\begin{array}{c}7 \\
43.8 \%\end{array}$ & $\begin{array}{c}19 \\
39.6 \%\end{array}$ & \\
\hline Weight Gain & $\begin{array}{c}9 \\
28.1 \%\end{array}$ & $\begin{array}{c}2 \\
12.5 \%\end{array}$ & $\begin{array}{c}11 \\
22.9 \%\end{array}$ & \\
\hline Nausea & $\begin{array}{c}2 \\
6.3 \%\end{array}$ & $\begin{array}{c}1 \\
6.3 \%\end{array}$ & $\begin{array}{c}3 \\
6.3 \%\end{array}$ & \\
\hline Headache & $\begin{array}{c}4 \\
12.5 \%\end{array}$ & $\begin{array}{c}2 \\
12.5 \%\end{array}$ & $\begin{array}{c}6 \\
12.5 \%\end{array}$ & \\
\hline Skin Rash & $\begin{array}{c}1 \\
3.1 \%\end{array}$ & $\begin{array}{c}1 \\
6.3 \%\end{array}$ & $\begin{array}{c}2 \\
4.2 \%\end{array}$ & 0.793 \\
\hline Tiredness & $\begin{array}{c}3 \\
9.4 \%\end{array}$ & $\begin{array}{c}1 \\
6.3 \%\end{array}$ & $\begin{array}{c}4 \\
8.3 \%\end{array}$ & \\
\hline Ataxia & $\begin{array}{c}1 \\
3.1 \%\end{array}$ & $\begin{array}{c}2 \\
12.5 \%\end{array}$ & $\begin{array}{c}3 \\
6.3 \%\end{array}$ & \\
\hline Total & $\begin{array}{c}32 \\
100.0 \%\end{array}$ & $\begin{array}{c}16 \\
100.0 \%\end{array}$ & $\begin{array}{c}48 \\
100.0 \%\end{array}$ & \\
\hline
\end{tabular}

reduction in phenytoin treated Group-A. Another study by Yasiry and Shorvon compared phenytoin efficacy with other antiepileptics and a mean efficacy of 50.2\% (95\% CI: 43.2-66.1\%) was found higher than our observations. ${ }^{13}$ In a study, Heller et al., had shown $51 \%$ efficacy by phenytoin after 6 months follow up with $3 \%$ adverse effect only. ${ }^{14}$

Phenytoin is used as a first-line drug in low and middleincome countries like India as it is low-cost drug and can be given as a single daily dose but no longer considered as a first-line agent in developed countries due to many adverse effects.
In the present study, $16(53.33 \%)$ patients had complete seizure freedom, $8(26.67 \%)$ patients had $\geq 50 \%$ seizure reduction and $6(20.00 \%)$ patients had $<50 \%$ seizure reduction in clobazam treated Group B. In a study by Schmidt et al., $40 \%$ had $>75 \%$ seizure reduction, $20 \%$ became seizure free, and adverse effects occurred in $40 \%$ of the patients. ${ }^{15}$ Allen et al., administered $30 \mathrm{mg}$ clobazam or placebo and showed $>50 \%$ seizure reduction in $59 \%$ of patients. ${ }^{16}$

Wildin et al., had observed $>50 \%$ reduction in seizure frequency in around $75 \%$ patients higher than our results with few side effects by using clobazam. ${ }^{17}$ Our findings were higher than a study conducted by Rupa et al., where seizure freedom was seen in $36.2 \%$ of patients with clobazam therapy for a period of 12 months. ${ }^{18}$

Another study by Mehndiratta et al., showed 64\% of patients after clobazam monotherapy were seizure free while $20 \%$ of patients had $\geq 50 \%$ seizure reduction with very less treatment failure. Our results close with the findings of Mehndiratta et al. ${ }^{10}$

Approximately $66.67 \%$ of patients in Group A and $33.33 \%$ of patients in Group B experienced adverse events (statistically non-significant) of mild-to-moderate severity such as drowsiness, weight gain, headache, tiredness, ataxia, nausea, skin rash.

The causality was assessed using Naranjo's Algorithm, which is one of the most widely used methods for evaluating adverse reactions and the severity of the ADRs using Hartwing and Siegel scale. None of these side effects warranted discontinuation of the therapy, treatment failure, or break through seizure. ${ }^{19,20}$ In majority of the patients, the ADRs were either self-limiting or resolved after dose adjustment and symptomatic treatments.

In another study also clobazam was considered safer with fewer side effects than phenytoin that supports our result. ${ }^{11}$ Many clinical data recommends that the risk of serious ADR is very low with clobazam as compared to phenytoin; known adverse effects are easily managed, predictable, generally dose-related, and reversible.

\section{Limitations of the study}

Limitation of the study was, it was undertaken in a single medical college with small number of population, and the duration of the study was short. Further studies may take up with larger study groups and for prolonged study periods.

\section{CONCLUSION}

Both the drugs had shown clinically and statistically significant reduction in seizure frequency in comparison 
with their respective baselines. However, intergroup comparison had validated that clobazam was statistically superior than phenytoin. Both the drugs were well tolerated but phenytoin had greater percentage of adverse events. Clobazam can be safely prescribed as monotherapy in epileptic patients.

\section{ACKNOWLEDGMENT}

The authors would like to thank the departments of Pharmacology, Radiology and General Medicine for their immense support towards this study.

\section{REFERENCES}

1. World Health Organization. Epilepsy Fact Sheet. Geneva: World Health Organization; 2019. Available from: https://www.who. int/news-room/fact-sheets/detail/epilepsy [Last accessed on 2019 Nov 15].

2. Montenegro MA, Arif H, Nahm EA, Resor SR Jr. and Hirsch LJ. Efficacy of clobazam as add-on therapy for refractory epilepsy: Experience at a U.S epilepsy centre. Clin Neuropharmacol. 2008;31(6):333-338.

https://doi.org/10.1097/WNF.0b013e31815cd960

3. Merritt $\mathrm{HH}$ and Putman TJ. A new series of anticonvulsant drugs tested by experiment in animals. Arch Neurol Psychiatry. 1938;39:1003-1015.

4. Mathur S, Sen S, Ramesh L and Kumar SM. Utilization pattern of antiepileptic drugs and their adverse effects, in a teaching hospital. Asian J Pharm Clin Res. 2010;3(1):55-59.

5. Glauser T, Ben-Menachem E, Bourgeois B, Cnaan A, Guerreiro C, Kalviainen R, et al. Updated ILAE evidence review of antiepileptic drug efficacy and effectiveness as initial monotherapy for epileptic seizures and syndromes. Epilepsia. 2013;10:1-13.

6. George J, Jose J, Kulkarni DA, Hanamantappa RR and Shalavadi CV. Evaluation of drug utilization and analysis of antiepileptic drugs at tertiary care teaching hospital. Indian J Pharm Pract. 2016;9(3):189-194.

7. Mane YV, Potey A, Bhide SS, Jalgaonkar SV and Ravat SH. Drug utilization pattern of antiepileptic drugs and direct and indirect cost estimation in the treatment of epilepsy at tertiary care hospital. Int J Inform Res Rev. 2015;2:759-764.

8. Badwaik RT, Mahajan MH, Borkar SA, Honrao R and Chopade SS. A drug utilization study of antiepileptic drugs use in a tertiary care hospital of Central India. J Contemp Med Dent. 2015;3(2):33-38.

9. Roy MK and Das D. Indian Guidelines on Epilepsy. Vol. 1. IAP Expert Committee Guidelines; 2013. p. 528-9.

10. Mehndiratta MM, Krishnamurti M, Rajesh KN and Singh G. Clobazam monotherapy in drug naïve adult patients with epilepsy. Seizure. 2003;12(4):226-228.

https://doi.org/10.1016/s1059-1311(02)00263-7

11. Clobazam has equivalent efficacy to carbamazepine and phenytoin as monotherapy for childhood epilepsy. Canadian study group for childhood epilepsy. Epilepsia. 1998;39(9):952-959. https://doi.org/10.1111/j.1528-1157.1998.tb01444.x

12. Dulac O, Figueroa D, Rey E and Arthuis M. Monotherapy with clobazam in epilepsies in children. Presse Med. 1983;12(17):1067-1069.

13. Yasiry Z, Shorvon SD. The relative effectiveness of five antiepileptic drugs in treatment of benzodiazepine-resistant convulsive status epilepticus: A meta-analysis of published studies. Seizure. 2014;23(3):167-174. https://doi.org/10.1016/j.seizure.2013.12.007

14. Heller A, Chesterman P, Elwes RD, Crawford P, Chadwick D, Johnson AL, et al. Phenobarbitone, phenytoin, carbamazepine or sodium valproate for newly diagnosed adult epilepsy: A randomized comparative monotherapy trial. J Neurol Neurosurg Psychiatry. 1995;58(1):44-50. https://doi.org/10.1136/jnnp.58.1.44

15. Schmidt $D$, Rohde M, Wolf $P$ and Roeder-Wanner U. Clobazam for refractory focal epilepsy. A controlled trial. Arch Neurol. 1986;43(8):824-826. https://doi.org/10.1001/archneur.1986.00520080064023

16. Allen JW, Jawad S, Oxley J and Trimble M. A Long Term Study of the Efficacy of Clobazam as an Antiepileptic Drug, Short Report. Royal Society of Medicine International Congress and Symposium Series No. 74; 1985. p. 139-40.

17. Wildin JD, Pleuvry BJ, Mawer GE, Onon T and Milington L. Respiratory and sedative effects of clobazam and clonazepam in volunteers. Br J Clin Pharmacol. 1990;29(2):169-177. https://doi.org/10.1111/j.1365-2125.1990.tb03616.x

18. Rupa J, Manjari T, Pooja G and Yogendra KG. Effect of clobazam as add on antiepileptic drug in patients with epilepsy. Indian J Med Res. 2014;140(2):209-215.

19. Naranjo CA, Busto U, Sellers EM, Sandor P, Ruiz L, Roberts EA, et al. A method for estimating the probability of adverse reactions. Clin Pharmacol Ther. 1981;30(2):239-245. https://doi.org/10.1038/clpt.1981.154

20. Hartwig SC, Siegel J and Schneider PJ. Preventability and severity assessment in reporting adverse drug reactions. Am J Hosp Pharm. 1992;49(9):2229-2232.

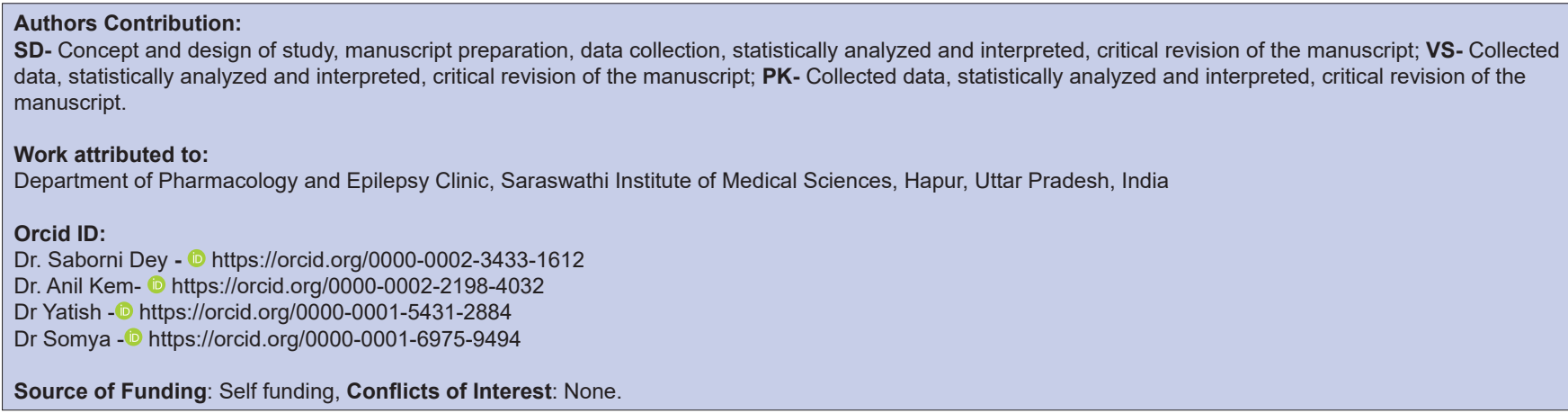

